\title{
Tetra Pak Recycling - Current Trends and New Developments
}

\author{
Jan Zawadiak, Szymon Wojciechowski*, Tomasz Piotrowski, Alicja Krypa \\ Department of Chemical Organic Technology and Petrochemistry, Silesian University of Technology, Gliwice, Poland \\ Email address: \\ szymon.wojciechowski@polsl.pl (S. Wojciechowski) \\ ${ }^{*}$ Corresponding author \\ To cite this article: \\ Jan Zawadiak, Szymon Wojciechowski, Tomasz Piotrowski, Alicja Krypa. Tetra Pak Recycling - Current Trends and New Developments. \\ American Journal of Chemical Engineering. Vol. 5, No. 3, 2017, pp. 37-42. doi: 10.11648/j.ajche.20170503.12
}

Received: April 3, 2017; Accepted: May 17, 2017; Published: May 20, 2017

\begin{abstract}
Tetra Pak packaging is considered an important source of high quality waste paper for pulp industry. Parallel to the fibre recovery a large quantity of PE-Al laminate is produced as by product. Reclaiming that perspective resource will be in focus of many pulp processing plants as conventional ways of disposing of such material are limited by new regulations. From many perspective technologies, only a few have achieved industrial level implementation.
\end{abstract}

Keywords: PE-Al Laminate, Tetra Pak, Delamination, Recycling

\section{Introduction}

Multi-material, paper based packaging for liquid food, commonly known as Tetra Pak, is produced by leading manufacturers: SIG, Combibloc, Elopak, Greatview and Tetra Pak. Such packaging is usually used for storage of perishable food products such as juice and dairy.

Tetra Pak packaging was introduced into the market for the first time by R. Rausing company in 1952. At first this packaging was made out of waxed paper and shaped as tetrahedral. Only after 1969, cuboidal packaging with aseptic properties was developed and in that form it evolved little to the shape that can be now recognized from the store shelves. [1]

Today Tetra Pak packaging is produced by laminating layers of: stiff paper, low density polyethylene (LDPE) and aluminium foil (Al).

In 2012, on the EU scale, this material was produced in quantity of $936382 \mathrm{Mg}$, from which $40 \%$ have been recycled and $29 \%$ used in energy recovery processes. [2]

Material recycling is a challenging task in case of Tetra Pak packaging. Obtaining high value products in compliance with process economy and Green Chemistry rules is still an unachieved goal for many companies. Wide variety of technological approaches signalize that none of currently applied solutions gained significant advantage.
The aim of this paper is to describe currently applied technologies enabling used Tetra Pak cartons (UTPC) to be recycled as well as new advances in that field.

\section{Tetra Pak Recycling Technologies}

\subsection{Tetra Pak Composition and Typical Usage}

Tetra Pak is produced by laminating together paper, LDPE and $\mathrm{Al}$ into one composite material. Paper, responsible for $75 \%$ of packaging mass is used to help ensure rigid shape of final product as well as to increase material strength. Al foil (5\%) is used because of its excellent barrier properties for agents such as light, oxygen, water vapour, odours and microorganisms. LDPE, used in $20 \%$, have many functions: protects paper layer from contacting with water; protects aluminium layer from direct contact with packaging content; bonds layers together and enables heat-sealing. Depending on the packaging type $\mathrm{Al}$ layer might not be present since some short-lived products do not benefit from its barrier properties during their intended storage time. On the other hand, products requiring extended shelf life can be subjected to heat treatment upon packaging if LDPE layers are replaced with PP. Additional polymers are also present, such as HDPE (cups and lids) as well as PET and PA film, reinforcing heat-sealed packaging edges. Also, a thin layer of polyurethane or poly (ethylene-co-methacrylic acid) (EMAA) might be used as adhesives, reinforcing bond 
between layers.

\subsection{Applied Industrial Technologies}

Technologies that have been successfully applied can be divided into two groups. Those that process the whole UTPC material as it is, and those that rely on hydropulping as the first step, separating cellulose fibre from PE-Al laminate.

\subsubsection{Processing Without Hydropulping}

Processing post-consumer Tetra Pak without hydropulping in most cases is possible only by means of energy recovery or by obtaining products of low quality (downcycling).

Widely understood energy recovery can be facilitated by incineration, gasification or pyrolysis, usually in a mix with other municipal solid waste. Treating sorted post-consumer Tetra Pak in such a way is not an efficient way of processing this resource with paper as the main ingredient. Relatively low heat of paper combustion (16 MJ/kg), usually significant water content and high ash value make this approach undesirable, especially under shrinking waste-paper market conditions.

Other means of treatment usually involve shredding UTPC and using such material as a filler in many applications from particle board to polymer concrete. The most common is laminated board production.

\section{Laminated board production}

Laminated board can be produced by shredding Tetra Pak to the particles sized 1-5 $\mathrm{mm}$ and hot-pressing of such material at $170^{\circ} \mathrm{C}$. The addition of lower quality polyolefin is a common practice since quantity of LDPE in Tetra Pak is not sufficient to guarantee desired mechanical properties. Composite obtained in the process is light and water-resistant with varying level of flexibility. Such product is introduced onto the market as a replacement for Oriented Strand Board, but current production volumes are negligible in comparison to the UTPC output. The most suitable raw material in this process is obtained from post-production waste, as the contamination from residual food products and high humidity are undesirable. [3]

Products of different shapes, such as roof tiles, edge protectors or core plugs, are also common.

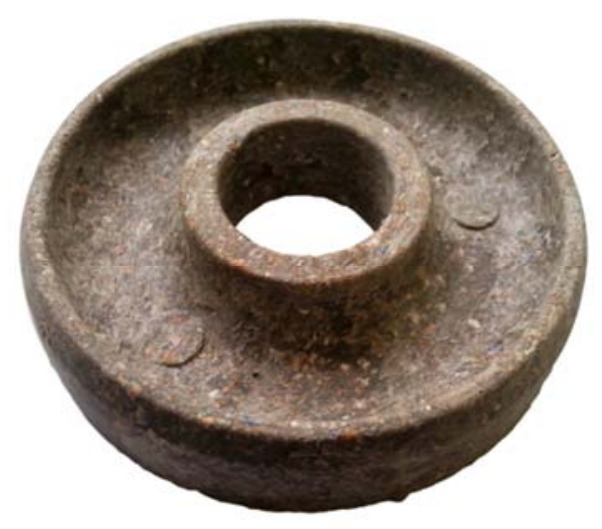

Figure 1. Core plug used to protect paper mother rolls during transportation.
Such products are manufactured under many trademarks in different countries: TECTAN ${ }^{\circledR}$, TeRO ${ }^{\circledR}$, Tetra K1 ${ }^{\circledR}$, T-Plak ${ }^{\circledR}$, Chiptec $\AA$, Tetrabuild $\AA$ but future development in housing construction will vary on improving fire resistance properties.

\subsubsection{Processing with Hydropulping}

The most mature technology regarding UTPC processing is hydropulping based on similar approach as in conventional waste paper recycling with minor changes during pulp separation from rejected PE-Al.

In the first step UTPC is usually cut into postcard-like size. In the next step material is directed to hydropulping process. Under action of high speed mixer or rotary drum in the presence of water at temperature from ambient to $50^{\circ} \mathrm{C}$ cellulose fibre adsorb water and form pulp. Mixture containing pulp and PE-Al laminate is then separated by sieving off undefibered material. Depending on particular system, additional steps might be taken in terms of pulp/PE-Al further purification. In modern technologies, fibre content in PE-Al product settles between 1 to 5\%. [4] Depending on the raw material purity, non-negligible amounts of other polymers can be found in end-product, such as: HDPE, PET, PA, PP and PVC. Cups and lids that may be responsible for up to $15 \%$ of $\mathrm{PE}-\mathrm{Al}$ mass may be easily separated by means of pneumatic sorting based on density difference. Despite some contamination sources, PE-Al is a clean, reproducible product that can be processed further.

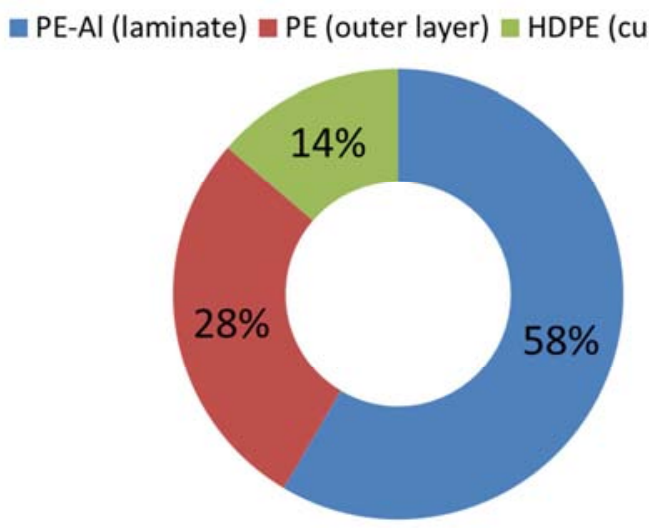

Figure 2. PE-Al composition obtained in hydropulping process as dry mass \% (excluding residual paper which varies from 1-15\%).

\section{a) PE-Al Energy recovery}

Many technologies that base on material recycling of PE-Al to high quality products have not been fully mature, yet. Due to more manageable raw material requirements, energy recovery processes have experienced significant growth in Europe in recent years. High heating value of PE-Al (ca. $40 \mathrm{MJ} / \mathrm{kg}$ ) makes this material an attractive fuel. It can be mixed with other fuels, or incinerated without processing. It is an interesting choice especially for cement industry as $\mathrm{Al}_{2} \mathrm{O}_{3}$ that is formed in the process is a desired component in cement production. In controlled conditions, LDPE burns in clean, environmentally friendly manner. Such 
fuel is free from elements: $\mathrm{S}, \mathrm{N}, \mathrm{F}, \mathrm{Cl}, \mathrm{Br}, \mathrm{P}$. [3] On the other hand, cement industry in Europe has reached its limit in terms of refuse-derived fuel (RDF) consumption forcing pulp industry to direct PE-Al to landfill sites or to search for alternative solutions like pyrolysis.

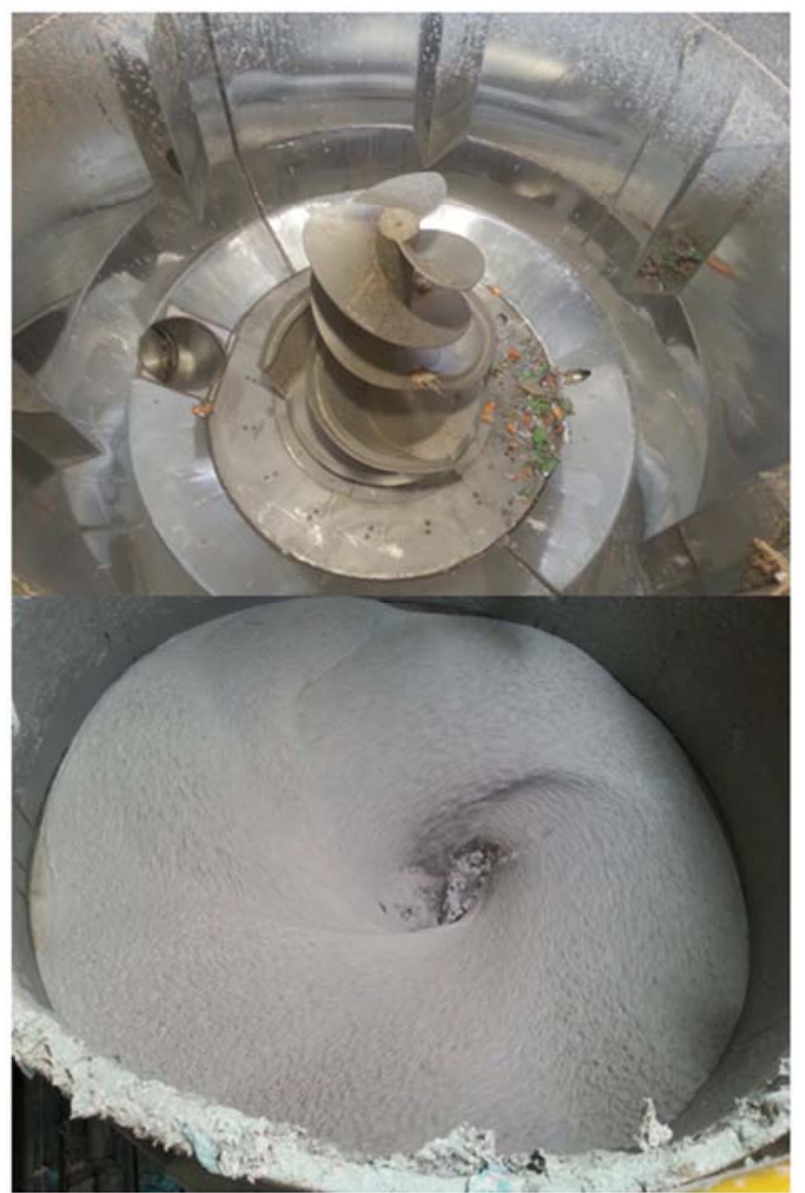

Figure 3. Vertical type hydropulper: empty (top); during UTPC processing (bottom).

\section{b) PE-Al Pyrolysis}

Pyrolysis is considered a better solution then direct incineration, but results are often far from satisfactory. In oxygen-free atmosphere PE-Al is heated to $400-800^{\circ} \mathrm{C}$. Many technical solutions have been applied from fluidized bed reactor or screw-conveyor reactor type to microwave assisted pyrolysis. In such conditions, PE degrades with release of gaseous products. [5,6].

Pyrolytic gas upon condensing heavier compounds is composed mostly of $\mathrm{CH}_{4}, \mathrm{H}_{2}$ and $\mathrm{C} 2-6$ hydrocarbons. Gas might be used directly to sustain pyrolysis process or can be used elsewhere.

Condensed fraction is a difficult substance to handle since it contains mixture of light boiling hydrocarbons with a high vapour pressure as well as heavy oil, and wax-like substances. Dust and emulsified water are usually also present. With specialized equipment, such mixture can be also used as fuel.

Solid product consists of a char like substance usually containing $60 \% \mathrm{Al}$. Depending on the amount of moisture and other oxygen containing substances in raw material, $\mathrm{Al}$ will be partially oxidized as it reacts with water at process temperature. Usually half of produced aluminium will be produced in A12O3 form. Such composition makes conventional $\mathrm{Al}$ recycling technologies unsuitable in processing of this material, which makes incineration the main direction of disposing of this product.

Very few technologies can recycle $\mathrm{Al}$ in its metallic form from such material. One of which is the solution developed by Alcoa Aluminio and TSL Ambiental based on plasma assisted Al melting. In temperatures ranging up to $2000^{\circ} \mathrm{C}$ both $\mathrm{Al}$ and $\mathrm{Al} 2 \mathrm{O} 3$ are melted which promotes proper droplet formation by liquid metal phase and enables efficient aluminium recycling from such low concentrated material.

Although by means of pyrolysis some material recycling can be achieved, all PE is lost in this energy consuming process.

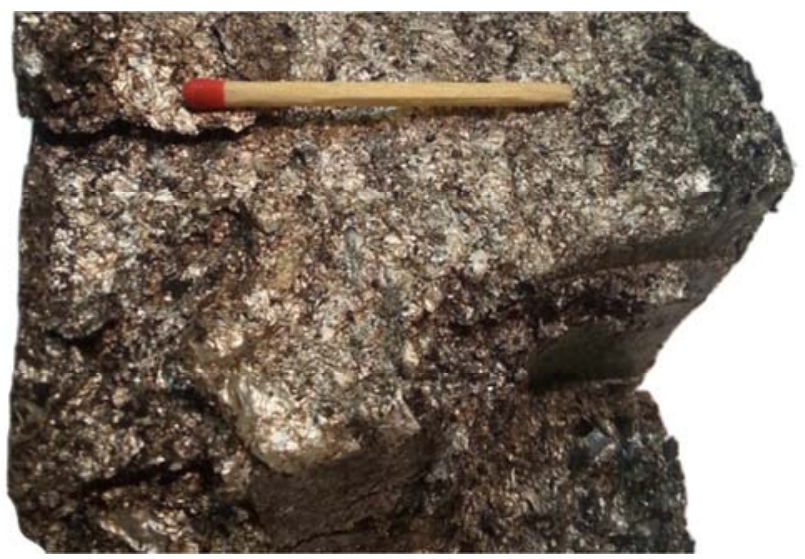

Figure 4. Solid product of pyrolysis process. Composition: $42,9 \%$ C; 36,9\% $A l_{\text {total }} ; 17,7 \% A l_{\text {met }}$.

\section{c) PE-Al Material recycling}

Material recycling with both: LDPE and Al recovery might be considered as a suitable option for environmental reasons. Technologies suitable for such task require custom equipment and have significant energy needs. Usually, also supplementary materials are consumed. Such conditions require high value products for the process to be economically justified.

\section{Direct forming into finished products}

One of the solutions of disposing of PE-Al is direct forming into finished products. There are many technologies and available products from simple hot-pressing during roof tile production to injection- or rotational-moulding upon PE-Al agglomeration and pulverization. [7, 8]

In case of simple and low energy consuming processes products are usually visually not appealing as aluminium flakes and uneven colouration introduced by HDPE, PP and PET contamination are clearly visible. More advance technologies can deliver high-end products with hardly visible, even texture and perfect reproduction of surface details. Such products can compete with those made out of virgin quality polymers, although high energy consumption is an important disadvantage for PE-Al. Marketing of processed $\mathrm{PE}-\mathrm{Al}$ products is the most difficult task today. $5000-10000$ 
$\mathrm{Mg}$, the usual annual PE-Al output for typical paper mill processing UTPC is a vast amount in terms of finished goods. Developing market for PE-Al products is necessary for wider implementation of direct PE-Al processing. Unfortunately, product applications are limited since PE used in Tetra Pak production is specified to be suited for film production, and therefore rigid objects made from PE-Al may possess undesirable properties such as low tensile strength or Young's modulus. Presence of aluminium particles in composite tends to reduce tensile strength further to ca. 10-11 MPa. [9]

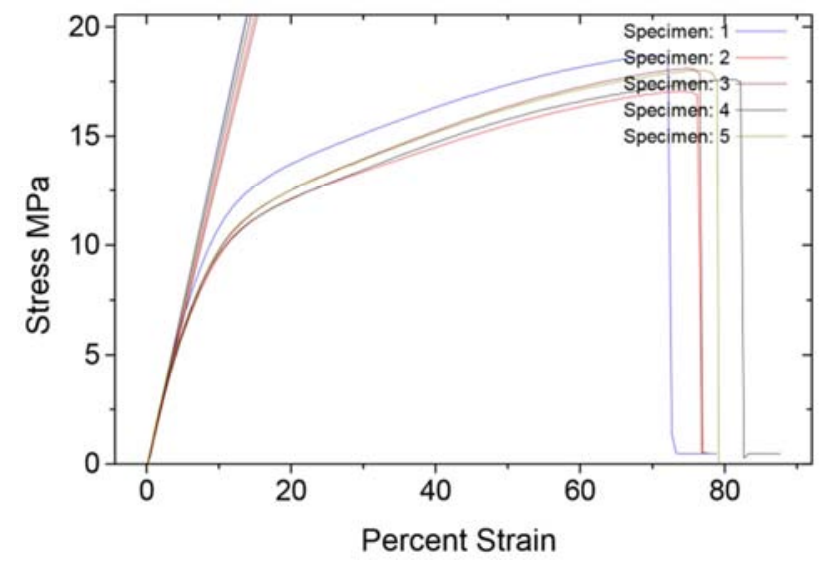

Figure 5. Tensile strength test of pure LDPE derived from UTPC. Strain at Max Load 75.590\%; Stress at Max Load 17.885 MPa; Young's Modulus $142.441 \mathrm{MPa}$.

\section{Acid based delamination}

Acid based delamination was the first technology to mature to the fully industrial stage and it is performed in China. In this approach, PE-Al is contacted with $18 \%$ formic acid solution in water at temperature $60-80^{\circ} \mathrm{C}$. In short time, under influence of mechanical action both layers separate, which is explained by partial Al dissolution by acid. Next, both materials are separated by sink-or-float basis, usually with a support of centrifugation. [10,11]

During delamination, formic acid undergoes reaction with $\mathrm{Al}$ and is consumed in the process. Depending on the process parameters $2-4 \%$ of $\mathrm{Al}$ can be dissolved. Nitric acid is added to the reaction mixture to preserve desired $\mathrm{pH}$ throughout consecutive process cycles. Parallel to the $\mathrm{Al}^{3+}$ ions accumulation in the solution, separation rate is decreasing. Such solution has to be then replenished with fresh formic acid and partially treated.

$\mathrm{Al}$ can be obtained in this process in a very pure form, but the final purity will partially depend on fibre content in the raw material.

On the other hand, LDPE fraction will contain HDPE in form of cups and lids if they are not removed before the process. PET contamination is also an important factor if it is present in the raw material. Finally, Al separation from PE-Al at the point of heat-seal is far from perfect, which will usually affect product purity and value.

Such technology can be applied also for PET-PE and PA-PE laminates recycling although it is less common since sink-or-float separation in that case is not efficient.

\section{Solvent based delamination}

Using solvent as a delamination agent is also a viable option, although to the best of authors' knowledge, no such technology has left the pilot stage yet. Solvent usually comprises mixed hydrocarbons with boiling point, low enough to facilitate efficient drying. Sink-or-float process is not an effective separation method in case of most solvent mixes as organic solvents usually do not have density high enough to float PE. In some cases, solvent mixtures containing water in separate phase can be used as efficient delamination agent while $\mathrm{Al}$ and $\mathrm{PE}$ separation might be achieved on phase boundary. [12]

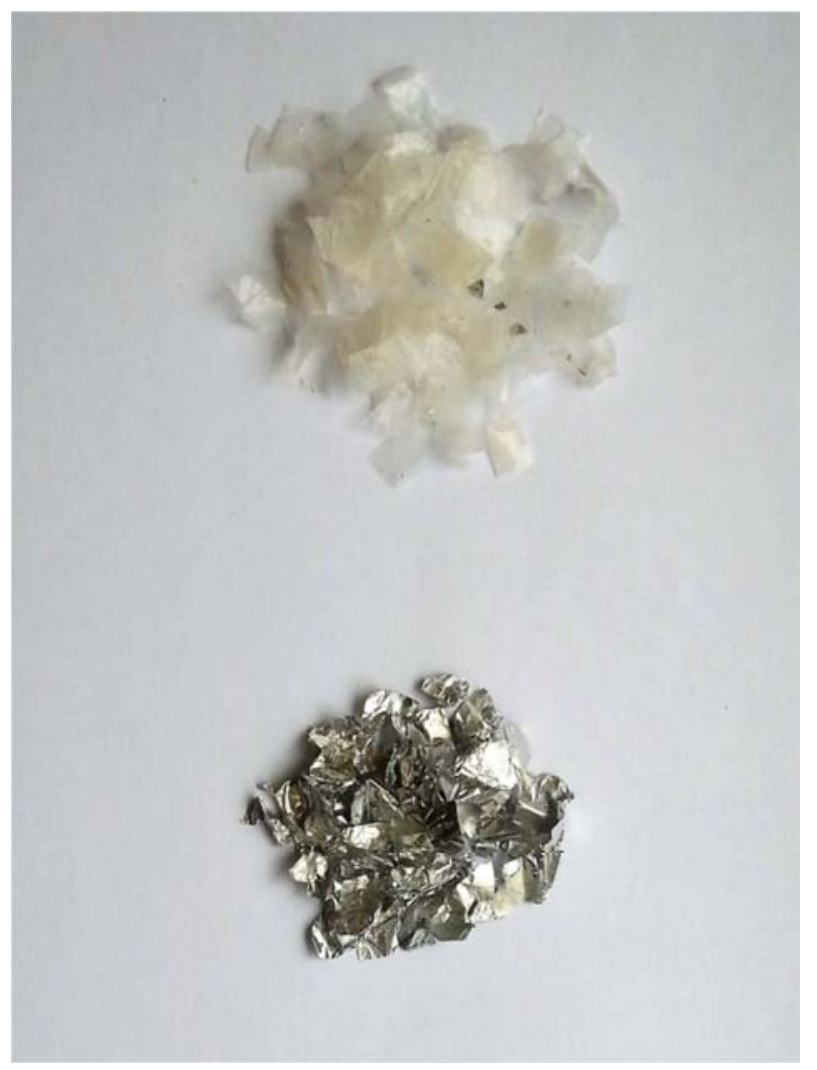

Figure 6. Products obtained from PE-Al laminate by delamination with $20 \%$ formic acid at $40^{\circ} \mathrm{C}$ : LDPE flakes containing some Al contamination (top); aluminium based fraction (bottom).

\section{Solvent based PE extraction}

The second most mature technology in terms of full material recycling is solvent based extraction. The idea is not a new concept, and dates back to the 1970s. [13] It is based on dissolving $\mathrm{PE}$ in an organic solvent at elevated temperature and separating undissolved particles such as Al, residual paper fibre, PET, HDPE, PA as well as sand and other contaminants.

This method offers the highest purity LDPE as the main product, as nearly full particle separation is achievable from polymer solution by means of a filtration, sedimentation or centrifugation. Purified solution can be then dried, spray-dried, dried under vacuum, steam dried, precipitated or treated with anti-solvent $[14,15]$. Reclaiming LDPE from solvent solution is the most energy consuming and technically challenging stage of the process. Thin layer evaporators (or falling film 
evaporator) are used most commonly for polymer drying as such equipment can operate in a continuous action and is far less complex than technologies such as spray- or vacuum-drying. On the other hand, thin layer evaporator requires high temperatures to operate with highly viscous solution. Full removal of solvent is usually problematic, and polymer degradation due to high temperature gradient is not something unheard-of. Lowering the quality of LDPE product could result in impaired economic performance, as the $\mathrm{Al}$ is produced in lower quantity.

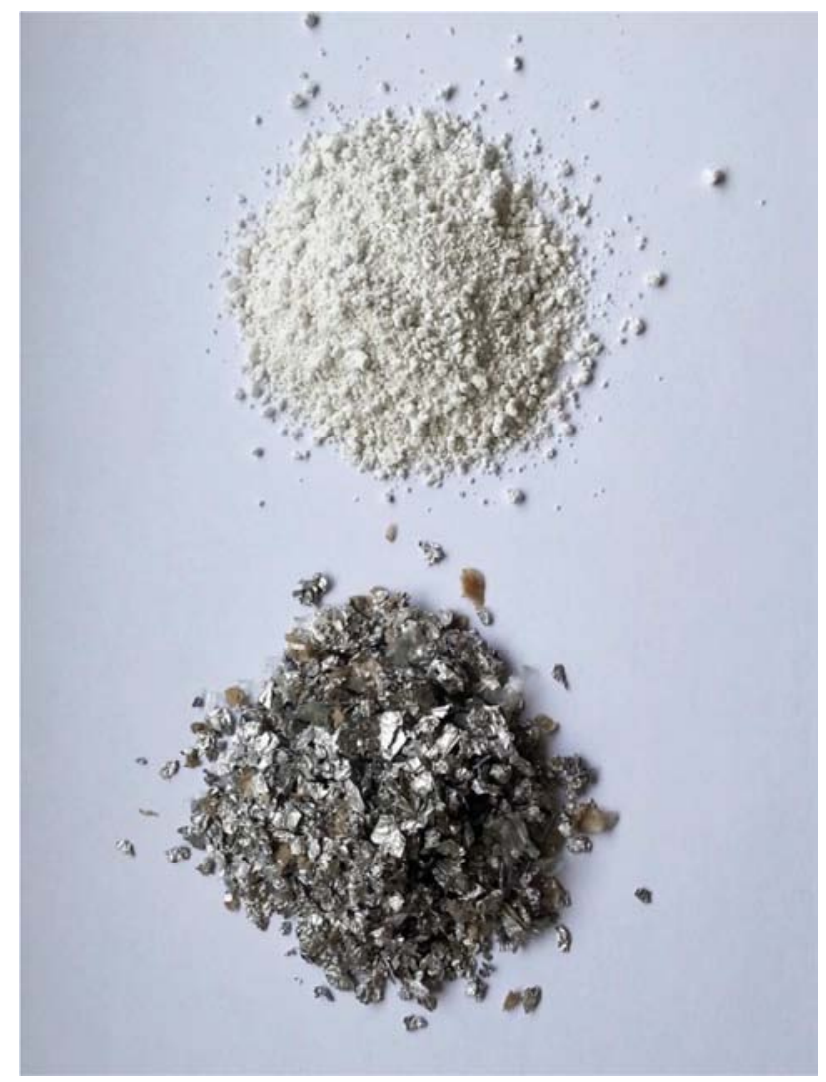

Figure 7. End-products obtained from PE-Al laminate by solvent extraction process: nearly white LDPE powder (top); aluminium based fraction: $59,9 \%$ $A l_{m e t}, 0,9 \% A l_{o x}, 35,2 \%$ organic impurities such as paper, PET, residual LDPE etc. (bottom).

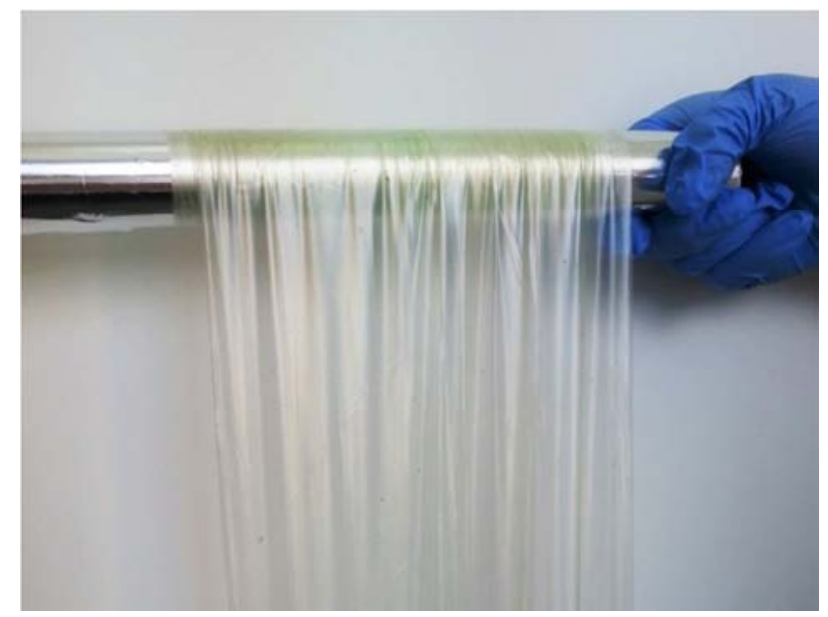

Figure 8. LDPE derived from PE-Al by solvent extraction could be successfully used in blown film extrusion process.
Al separated from the LDPE solution along with other solids may contain up to $60 \%$ by mass of residual solvent that will require drying. Additional wash with fresh solvent enables reduction of residual LDPE content. Depending on PE-Al purity, produced Al can contain different levels of organic carbon contamination. Such product before re-melting into ingots will usually require additional treatment, by such means as pyrolysis.

\section{Conclusion}

Processing of UTPC is rising rapidly driven by stricter regulations in terms of waste disposal, as well as by decreasing supply of waste paper in digital era. PE-Al will have growing presence in plastic recycling as the depleting capacity for energy recovery will be shifted towards truly unrecyclable materials. An important factor that will shape the industry is the possibility to expand the market for finished goods directly made out of PE-Al. If the demand for such products does not develop to the tens of thousands $\mathrm{Mg}$ annually, rising incentives will be observed for further development of delamination or extraction based technologies.

\section{References}

[1] R. Rausing, "Method of packaging sterile filling material under aseptic conditions." U.S. Patent No. 3466841, 1969.

[2] M. Groven, D. Hansen, I. Thorsen "Environmental Status Report 2012" Elopak AS Group, [cited 2017 Mar 28]. Available from: www.elopak.com/resources/publications/Env ironmental_Report_2012.pdf.

[3] K. Korniejenko, S. Kuciel, J. Mikuła. "Ocena możliwości wytwarzania płyt dla potrzeb budownictwa ze zużytych opakowań typu tetra-pak." Archives of Foundry Engineering 10, 2010: pp. 119-124.

[4] A. Biel-Tyralska, T. Tyralski. "Przerób opakowań papierowych po płynach spożywczych." Przegląd Papierniczy 69.3; 2013: pp. 159-165.

[5] A. Korkmaz, "Pyrolysis of the tetra pak." Waste management 29.11, 2009: pp. 2836-2841.

[6] W. Chao-Hsiung, C. Hwa-Shan "Pyrolysis of tetra pack in municipal solid waste." Journal of Chemical Technology and Biotechnology 76.8, 2001: pp. 779-792.

[7] C. Lopes, M. Carmo Gonçalves, M. Felisberti "Blends of poly (ethylene terephthalate) and low density polyethylene containing aluminium: A material obtained from packaging recycling." Journal of Applied polymer science 106.4, 2007: pp. 2524-2535.

[8] M. Hidalgo "Manufacturing rigid board by packaging waste containing aluminum and polyethylene". J Sci Ind Res. 70, 2011: pp. 232.

[9] Tetra Pak India Pvt. Ltd. "High quality fibre from Tetra Pak cartons". New Dehli, Paperex 2015 [cited 2017 Mar 28]. Available from: www.tetrapak.com/in/about/newsarchive/tetr apak-at-paperex 2015. 
[10] Y. Dahai "Optimizing and developing a continuous separation system for the wet process separation of aluminum and polyethylene in aseptic composite packaging waste." Waste Manag Res. 35, 2015: pp. 21-28.

[11] X. Minghui "Life cycle assessment of the recycling of Al-PE (a laminated foil made from polyethylene and aluminum foil) composite packaging waste." Journal of Cleaner Production. 112, 2016: pp. 4430-4434.

[12] S. Zhang, L. Zhang, K. Luo, Z. Sun, X. Mei, "Separation properties of aluminium-plastic laminates in post-consumer Tetra Pak with mixed organic solvent." Waste Manag Res. 32(4), 2014: pp. 317-22.
[13] R. Goss, "Method of reclaiming stock from waste material." U.S. Patent No 3595741, 1971.

[14] W. Zacherle, "Verfahren zur Herstellung von Zielpolymerprodukten aus kunststoffhaltigen Materialien und nach diesem Verfahren erhältliche körnige oder pulverförmige Zielpolymerprodukte." German Patent No. 102014114831, 2016.

[15] W. Lindner, "Method and installation for separating individual valuable materials from mixed, in particular milled, plastic waste." U.S. Patent No. 9469049, 2016. 